\title{
BMJ Open Neighbourhood effects on obesity: scoping review of time-varying outcomes and exposures in longitudinal designs
}

\author{
Laurence Letarte (10 , ${ }^{1,2}$ Sonia Pomerleau, ${ }^{2,3}$ André Tchernof, ${ }^{3,4}$ Laurent Biertho, ${ }^{4,5}$ \\ Edward Owen D Waygood, ${ }^{6}$ Alexandre Lebel ${ }^{1,2}$
}

To cite: Letarte L,

Pomerleau S, Tchernof A, et al. Neighbourhood effects on obesity: scoping review of time-varying outcomes and exposures in longitudinal designs. BMJ Open 2020;10:e034690. doi:10.1136/ bmjopen-2019-034690

- Prepublication history and additional material for this paper are available online. To view these files, please visit the journal online (http://dx.doi. org/10.1136/bmjopen-2019034690).

Received 03 October 2019 Revised 15 January 2020 Accepted 10 February 2020

A Check for updates

(C) Author(s) (or their employer(s)) 2020. Re-use permitted under CC BY-NC. No commercial re-use. See rights and permissions. Published by BMJ.

For numbered affiliations see end of article.

\section{Correspondence to}

Dr Alexandre Lebel;

alexandre.lebel@criucpq.ulaval. ca

\section{ABSTRACT}

Context and objectives Neighbourhood effect research on obesity took off in the early 2000 s and was composed of mostly cross-sectional observational studies interested in various characteristics of the built environment and the socioeconomic environment. To limit biases related to self-selection and life course exposures, many researchers apply longitudinal designs in their studies. Until now, no review has specifically and exclusively examined longitudinal studies and the specific designs of these studies. In this review, we intend to answer the following research question: how are the temporal measurements of contextual exposure and obesity outcomes integrated into longitudinal studies that explore how neighbourhoodlevel built and socioeconomic environments impact adult obesity?

Design A systematic search strategy was designed to address the research question. The search was performed in Embase, Web of Science and PubMed, targeting scientific papers published before 1 January 2018. The eligible studies reported results on adults, included exposure that was limited to neighbourhood characteristics at the submunicipal level, included an outcome limited to obesity proxies, and reported a design with at least two exposure measurements or two outcome measurements. Results This scoping review identified 66 studies that fit the eligibility criteria. A wide variety of neighbourhood characteristics were also measured, making it difficult to draw general conclusions about associations between neighbourhood exposure and obesity. We applied a typology that classified studies by whether exposure and outcome were measured as varying or fixed. Using this typology, we found that 32 studies reported both neighbourhood exposure and obesity outcomes that were varying in time; 28 reported varying outcomes but fixed exposures; and 6 had fixed outcomes and varying exposures.

Conclusion Our typology illustrates the variety of longitudinal designs that were used in the selected studies. In the light of our results, we make recommendations on how to better report longitudinal designs and facilitate comparisons between studies.

\section{BACKGROUND}

Before the emergence of ecological models for weight change, ${ }^{1-3}$ obesity was mostly considered an individual responsibility.

\section{Strengths and limitations of this study}

To our knowledge, this is the first scoping review focusing on the designs of longitudinal studies of neighbourhood effect on obesity.

- This study proposes a typology to that classifies longitudinal studies by their design.

- The descriptive nature of a scoping review excludes quantitative analyses of the results.

- This scoping review excludes studies on children, which limits its scope but increases the homogeneity of the results.

Efforts to combat the obesity epidemic were therefore focused on trying to influence the behaviours of individuals to either reduce their caloric intake or increase their caloric expenditure, or both. However, such public health interventions did not have the expected results. ${ }^{4}$ Worldwide, adult populations have shown increasing rates of obesity prevalence, although a slower rate has been observed in high-income countries. ${ }^{5} 6$ In children, trends in obesity prevalence have plateaued in high-income countries but are steadily increasing in East and South Asia. ${ }^{7}$

Due to the mitigated success from the interventions that focused on individuals, some researchers expanded their focus by including the contextual factors in the causal web that may lead to obesity. Among the many levels of contextual factors, those related to neighbourhoods quickly became aspects of interest for reasons both theoretical and practical. The observational theory that being overweight is heterogeneously geographically distributed on the neighbourhood scale is a strong incentive for researchers to focus on the contextual influences that occur close to one's residence. ${ }^{8}$ Also, the increase in obesity prevalence correlates over time with strong global contextual changes. A number of these changes include trade liberalisation, economic growth and rapid urbanisation, 
which impact the shape and dynamics of neighbourhoods. ${ }^{9}$ Among the more practical reasons for focusing on the neighbourhood level is the hypothesis that the home environment is relatively easier to influence compared with the global food market or industrialisation. Moreover, in some countries, local and national governments have the legislative and regulatory powers to plan neighbourhoods. They are also responsible for health policies and services, which act as incentives for the government to lower healthcare costs and increase well-being by using contextual interventions.

Neighbourhood effect research on obesity grew in popularity in the early 2000s, ${ }^{10}$ consisting of mostly cross-sectional observational studies. These studies were focused on various characteristics of the built environment (eg, dwelling density, street connectivity, land use mix and food availability) and the socioeconomic environment (eg, deprivation, safety and social cohesion) and their effect on different obesity proxies (OPs) (eg, Body Mass Index (BMI), weight and waist circumference). The last two decades saw the publication of a substantial number of such studies. ${ }^{10-19}$ As of today, recent literature reviews specifically interested in the neighbourhood level have identified urban sprawl (positively) and land use mix (negatively) to be associated with weight, only in North America. ${ }^{10}$ A very recent literature review of longitudinal studies on built environment and cardiometabolic health also found strong evidence for the impact of walkability on obesity. ${ }^{20}$ However, authors have also reported methodological challenges, such as self-selection bias and the lack of life course exposure, and have suggested improving neighbourhood effect studies by using longitudinal designs (ie, using repeated measures of outcome and/or exposure) in order to move towards causality models. ${ }^{101421}$

Self-selection is a bias that can be introduced when individual residential localisation choices are related to individual obesity outcomes. ${ }^{22} 23$ For instance, people who enjoy physical activity might prefer residential neighbourhoods where many opportunities for such activities exist. People who enjoy travelling by car might prefer carfriendly neighbourhoods compared with those who prefer walking. ${ }^{24}$ These preferences and behaviours are often associated with obesity outcomes, but the time sequence between residential choice and weight gain cannot be disentangled in cross-sectional studies. In addition to the temporal sequence problem, cross-sectional studies have a limited capacity to examine the cumulative effect of neighbourhood exposure on an individual. ${ }^{22} 2526 \mathrm{An}$ unhealthy obesity status can be the result of a very gradual weight gain. This potentially long latency, combined with the effect of frequent residential moving, is not captured by the current studies on neighbourhood exposure..$^{25} 27$

The ability of longitudinal studies to control for selfselection bias and life course exposure depends in part on their design, that is, how outcome and exposure measurements are considered in time. Additionally, although some reviews of neighbourhood effects on obesity are interested in longitudinal studies, no review was specifically devoted to the specific designs that were used.

\section{RESEARCH QUESTION AND OBJECTIVES}

This scoping review was specifically designed to answer the following research question: how are the temporal measurements of contextual exposure and obesity outcomes integrated into longitudinal studies that explore how neighbourhood-level built and socioeconomic environments impact adult obesity?

To address this research question, the specific objectives of this review were to

1. Detail the number of studies investigating longitudinal neighbourhood effects on obesity status and to describe their general characteristics.

2. Describe and classify the study designs used to investigate longitudinal neighbourhood effects on obesity status.

3. Carry out a qualitative overview of the associations between neighbourhood exposure and obesity status among studies that apply a longitudinal design.

\section{MATERIALS AND METHODS}

We decided to use a scoping review approach because the large number of study designs that were used in the literature makes it difficult to sum and compare results quantitatively. ${ }^{28}$ Methods for this review are described in greater detail in the protocol. ${ }^{29}$ A concise description of the methods is provided in the following sections.

\section{Systematic search strategy}

A systematic search strategy was designed to reflect the research question as closely as possible and to collect all possible studies relevant to this field of research while screening for the eligibility criteria described in table 1 .

A search strategy was drafted by an experienced librarian (Frédérick Bergeron) and completed by the research team. The final search strategy involved identifying five keywords specifically related to the research question and articulated using Boolean operators:

Outcome terms AND longitudinal design terms AND (geographical context terms AND (social environment exposure terms OR physical environment exposure terms)).

This research strategy was modified to fit the search terms specific to three scientific citation index databases: Embase, Web of Science and PubMed. The full search strategy for PubMed is presented as an example in online supplementary file 1 . Only peer-reviewed literature that was published in referenced journals in English were considered. The search was performed in February 2018 for scientific papers published before 1 January 2018.

\section{Screening and eligibility}

The selection process was performed independently by two investigators (LL an SP). Kappa correlation was calculated to assess the interinvestigator agreement for selecting 
Table 1 Eligibility criteria for selection of publications (modified from the population, intervention, comparison, outcome framework $)^{27}$

\section{Criteria}

Population

Exposure

\section{Description}

Eligible study populations were composed of adults between 18 and 65 years of age. At least two obesity proxies and/or neighbourhood characteristics must have been measured during adulthood (18-65 years old); other measurements may be collected in childhood, youth or older age.

Exposure was measured by any indicator of neighbourhood socioeconomic and/or built environment, where neighbourhood is defined as an administratively delimited geographical area enclosing the participant's residence, a buffer-delimited area around the participant's residence or a perceived area delimited by the participant. The geographical area must have been defined at the neighbourhood level, which is smaller than a municipal area.

\begin{tabular}{|c|c|}
\hline Outcome & $\begin{array}{l}\text { The term 'obesity' is generally used to refer to the accumulation of body fat } \\
\text { and can be measured in numerous ways. Eligible studies were those reporting } \\
\text { measured or self-reported OP such as total body weight, Body Mass Index, } \\
\text { waist circumference, waist:hip ratio and/or skin fold thickness (with no specific } \\
\text { thresholds). In this review, any study considering obesity status as an outcome } \\
\text { was included. }\end{array}$ \\
\hline Study design & $\begin{array}{l}\text { The studies must have included a longitudinal perspective in the measurement } \\
\text { of the exposure and/or outcome. For example, studies applying the following } \\
\text { designs were considered longitudinal: case-control studies and cohort } \\
\text { studies, where exposure is measured at different points in time or classified } \\
\text { as a pattern over time; or experimental or quasi-experimental schemes, where } \\
\text { participants are exposed to different living environments over time. Cross- } \\
\text { sectional and ecological studies were systematically excluded. Study designs } \\
\text { that focused only on life course changes in obesity status without measuring } \\
\text { contextual exposure were not included in this review. }\end{array}$ \\
\hline
\end{tabular}

articles according to the title and abstract. Disagreements were resolved by attempting to reach a consensus between the two investigators. When a consensus could not be reached, a third observer (AL) was consulted to make a final decision. Most of the articles excluded at this point were ecological studies, studies with exposures measured at a scale other than the neighbourhood, and studies with outcomes that were not obesity status. Pertinent articles from the reference list of included papers were also added to the screened records.

\section{Charting}

The charting process was conducted according to the steps described in the previously published protocol. ${ }^{29}$ The construction of the chart also includes an iterative procedure of improvement, in order to consider other types of longitudinal designs that were not expected prior to the charting.

In its final form, the charting table contained the following information, extracted by one investigator (LL):

- Basic characteristics (year published, country of data collection, target population, type of outcome measure and exposure measure (type and neighbourhood unit)).

- Longitudinal characteristics (number of outcome measures, number of exposure measures, residential mobility of the population, change in neighbourhood characteristics, typology of study designs and statistical analysis).

- Direction and statistical significance of reported associations.

Results were synthesised by grouping studies according to their basic and longitudinal characteristics and then summarising their overall findings by analysing the reported associations.

\section{Patient and public involvement}

This research was done without patient involvement. Patients were not invited to comment on the study design and were not consulted to develop patient-relevant outcomes or to interpret the results. Patients were not invited to contribute to the writing or editing of this article for readability or accuracy.

\section{RESULTS}

\section{Publication selection}

Citations collected from the database searches were managed using EndNote X7.5. Duplicates were deleted. A flowchart of the selection process is presented in figure 1 . From the 12757 identified studies, after screening for relevant titles, abstracts and full manuscripts, 66 articles that fitted the eligibility criteria were selected. ${ }^{30-95}$ Summary characteristics are shown in table 2 and 


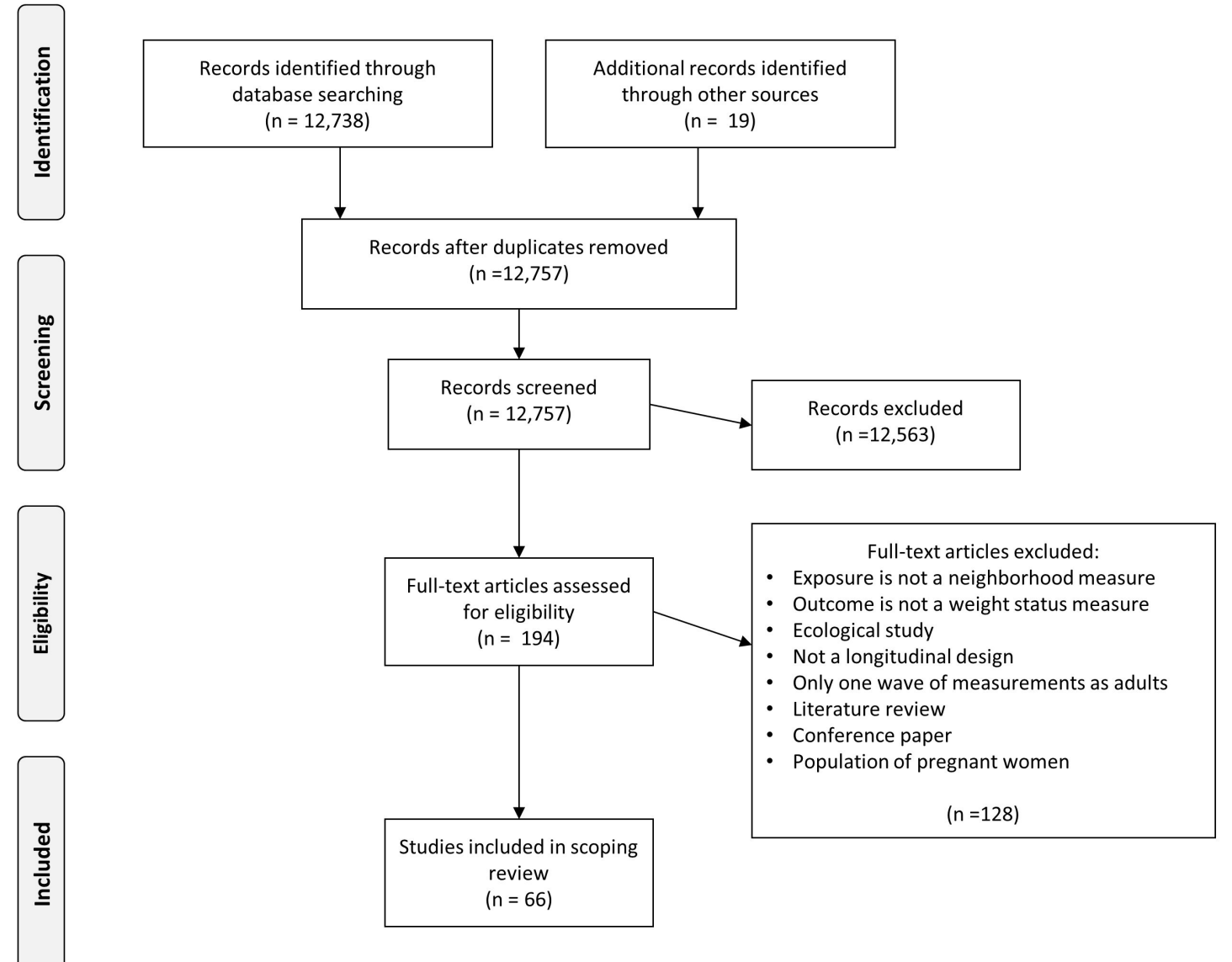

Figure 1 Flowchart of the article selection process.

complete characteristics of the studies are shown in online supplementary file 2 .

\section{Basic characteristics \\ Year published}

The selected studies were published over a relatively short time span, with the earliest publication in 2005 (figure 2). A general increasing pattern was observed, with a greater number of studies published each year. A particularly notable increase was observed for the last year of the review period (20 papers in 2017).

\section{Countries of origin}

Among the selected articles, the studied populations were not particularly diverse. The majority of studies were from North America $(79 \%, \mathrm{n}=52)$, and more specifically from the USA (56\%, n=37). Of the non-American study populations, seven $(11 \%)$ were European, two (3\%) were from Asia and five $(8 \%)$ were Australian.

\section{Target population}

We focused on adult populations, which have more stable weight status patterns than children. Thus, the selection criteria were set to include only studies in which two measurements were collected for OPs and/or neighbourhood exposure during adulthood (18-65 years old). The majority of studies $(n=33)$ examined non-specific adult populations. Six studies examined young adults (generally younger than 35 years old), while eleven other studies were focused on older adults (generally older than 45 years old). Fourteen studies also chose specific subgroups of the adult population that are susceptible to a differentiated neighbourhood effect compared with the general adult population (women, African-American women, people with diabetes and migrants). Fourteen studies stratified their results for gender, four for race and two for urban/rural places of residence.

\section{Outcome measurements}

The studies presented in this review were selected for outcomes associated with obesity. BMI was used as an outcome by $76 \%$ ( $\mathrm{n}=50$ ) of the studies, while waist circumference (or a ratio associated to waist and hip circumference) was used by $8 \%(n=5)$ of the studies (table 2$)$. Eleven per cent $(n=7)$ used both BMI and waist circumference. One study included measurements of subcutaneous adipose tissue and visceral adipose tissue (VAT) ${ }^{64}$

\section{Exposure measurements}

Each of the selected studies was classified according to the primary exposure that was examined. About half the studies fell into the built environment category (49\%, $\mathrm{n}=32$ ) and slightly fewer fell into the socioeconomic indicators category $(46 \%, \mathrm{n}=30)$. A small proportion of studies included both types $(6 \%, \mathrm{n}=4)$. Table 3 shows all 
Table 2 Distribution of the included studies, their overall findings and some design characteristics

\begin{tabular}{|c|c|c|c|c|c|c|}
\hline \multirow[b]{3}{*}{ Characteristics } & & & \multicolumn{4}{|c|}{ Overall study findings } \\
\hline & \multicolumn{2}{|c|}{ Included studies } & \multirow{2}{*}{$\begin{array}{l}\text { Null } \\
\mathrm{N}\end{array}$} & \multirow{2}{*}{$\begin{array}{l}\text { Mixed } \\
\mathrm{N}\end{array}$} & \multirow{2}{*}{$\begin{array}{l}\text { Expected } \\
\mathrm{N}\end{array}$} & \multirow{2}{*}{$\begin{array}{l}\text { Studies with } \\
\text { expected } \\
\text { findings (\%) }\end{array}$} \\
\hline & $\mathbf{N}$ & $\%$ & & & & \\
\hline All & 66 & 100 & 30 & 13 & 23 & 35 \\
\hline \multicolumn{7}{|l|}{ Outcome } \\
\hline BMI & 50 & 76 & 20 & 11 & 19 & 38 \\
\hline BMI and waist circumference & 7 & 11 & 6 & 1 & . & . \\
\hline Waist circumference & 5 & 8 & 2 & . & 3 & 60 \\
\hline Weight & 3 & 5 & 2 & 1 & . & . \\
\hline Adipose tissue volume & 1 & 2 & . & . & 1 & 100 \\
\hline All & 66 & 100 & & & & \\
\hline \multicolumn{7}{|l|}{ Type of attribute } \\
\hline Built environment & 32 & 49 & 17 & 8 & 7 & 22 \\
\hline Socioeconomic & 30 & 46 & 11 & 4 & 15 & 50 \\
\hline Both & 4 & 6 & 2 & 1 & 1 & 25 \\
\hline All & 66 & 100 & & & & \\
\hline \multicolumn{7}{|l|}{ Geographic unit } \\
\hline Census limits & 25 & 38 & 9 & 5 & 11 & 44 \\
\hline Euclidean Buffer & 13 & 20 & 8 & 1 & 4 & 31 \\
\hline Other & 10 & 15 & 6 & 3 & 1 & 10 \\
\hline Administrative limits & 9 & 14 & 4 & 1 & 4 & 44 \\
\hline Network buffer & 7 & 11 & 3 & 2 & 2 & 29 \\
\hline Self-reported & 2 & 3 & . & 1 & 1 & 50 \\
\hline All & 66 & 100 & & & & \\
\hline \multicolumn{7}{|l|}{ Residential mobility } \\
\hline Stayers and movers & 46 & 70 & 20 & 9 & 17 & 37 \\
\hline Stayers & 12 & 18 & 7 & 1 & 4 & 33 \\
\hline Stratified & 6 & 9 & 1 & 3 & 2 & 33 \\
\hline Movers & 2 & 3 & 2 & . & . & . \\
\hline All & 66 & 100 & & & & \\
\hline \multicolumn{7}{|c|}{ Change in neighbourhood characteristics } \\
\hline No & 38 & 58 & 13 & 8 & 17 & 45 \\
\hline Yes & 28 & 42 & 17 & 5 & 6 & 21 \\
\hline All & 66 & 100 & & & & \\
\hline \multicolumn{7}{|l|}{ Typology } \\
\hline Varying Outcome-Varying Exposure & 32 & 49 & 18 & 6 & 8 & 25 \\
\hline Varying Outcome-Fixed Exposure & 28 & 42 & 10 & 7 & 11 & 39 \\
\hline Fixed Outcome-Varying Exposure & 6 & 9 & 2 & . & 4 & 67 \\
\hline All & 66 & 100 & & & & \\
\hline
\end{tabular}

BMI, Body Mass Index.

associations measured in all included studies $(\mathrm{n}=481)$ and groups them into indicator categories. Food environment indicators appeared most often $(46 \%, \mathrm{n}=223)$, followed by area deprivation $(14 \%, \mathrm{n}=66)$, green spaces $(8 \%, n=40)$, socioeconomic composite index $(7 \%, n=34)$ and security indicators $(5 \%, \mathrm{n}=25)$. The indicators used were widely varied in all the categories. For example, some food environment indicators focused on assessing healthy food environments, such as grocery store and supermarket densities, ${ }^{3063}$ and others focused on fastfood restaurant and convenience store densities. ${ }^{66}{ }^{91}$ For composite indexes, authors applied an array of indexing 


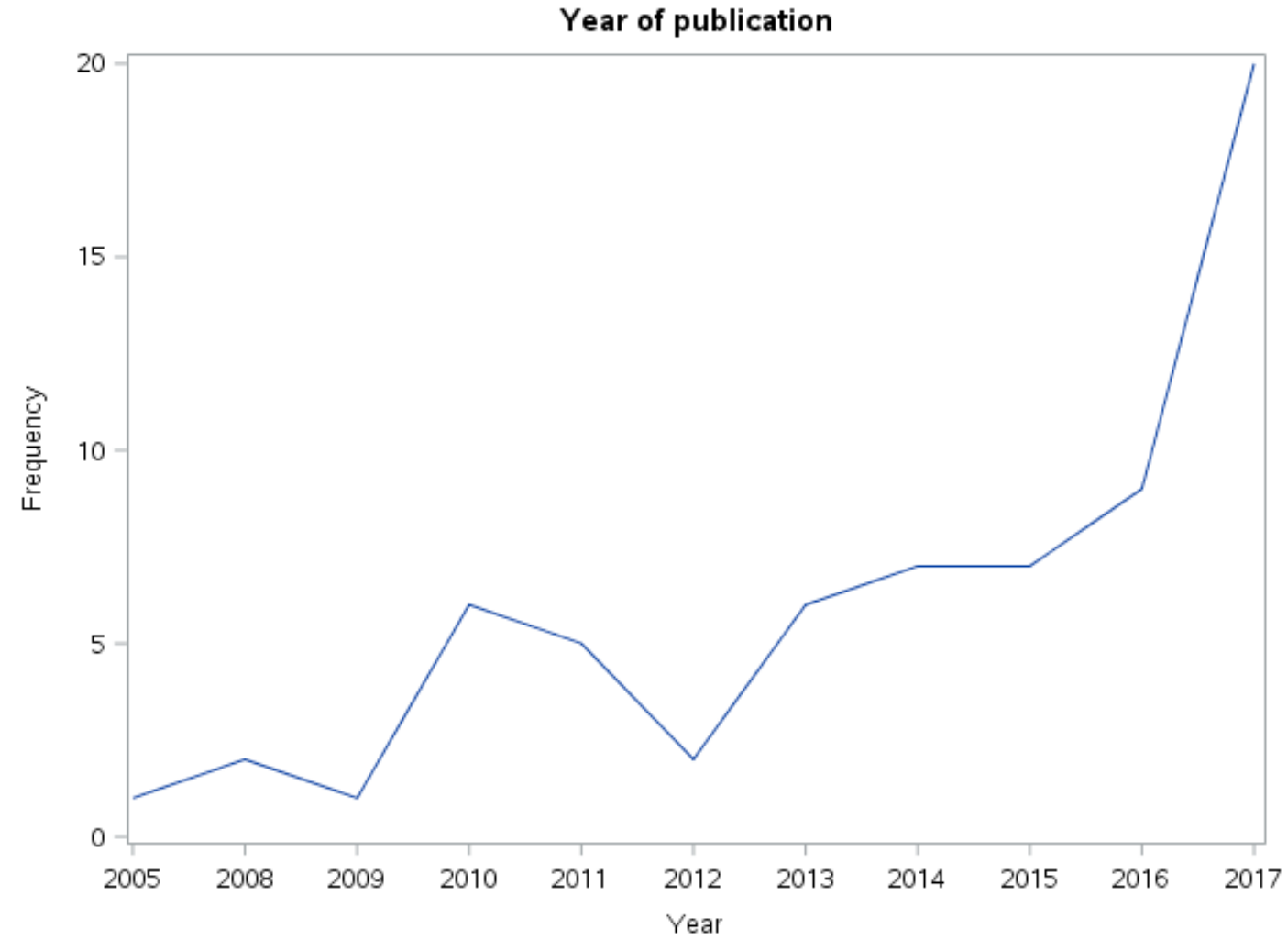

Figure 2 Publication year of selected longitudinal studies of neighbourhood effect on obesity.

methods, from pre-existing indexes ${ }^{51} 7885$ to summing different indicators ${ }^{43} 7181$ or using principal component analyses. ${ }^{46} 5575769096$

There was also a large amount of variability in the choice of neighbourhood units that were used to calculate exposure. The neighbourhood areas most often used were those defined by census limits $(n=25,38 \%)$, but quite a few studies relied on measurements such as Euclidean distance $(\mathrm{n}=13,20 \%)$ or network distance $(\mathrm{n}=7,11 \%)$, with a radius ranging from $100 \mathrm{~m}$ to $5 \mathrm{~km}$ around the individual's residence. Only two studies (3\%) asked participants for a self-reported neighbourhood area, and one study defined a neighbourhood as a participant's activity space, including non-residential neighbourhood exposure.

\section{Longitudinal characteristics}

The included studies applied longitudinal designs, meaning that more than one measurement of neighbourhood exposure or outcome in time was applied. Although all of the studies fit under the general definition of a longitudinal design, a few characteristics related to repeated measures and time allowed them to be categorised into subgroups.

\section{Number of outcome measurements}

There was wide variation in the number of outcomes measured among the selected studies. Six studies included only one outcome measurement, of which most were interventions or community trials. Thirty studies included two outcome measurements and 30 others included three or more different measurements. Among those, Laraia et $a l,{ }^{63}$ who studied the impact of food environment on weight change in a population of patients who were clinically followed up for diabetes, reported a median of 17 BMI measurements for the patients enrolled, with the number of measurements ranging from 10 to 27. This study reported the highest number of outcome measurements of all the studies selected for this review.

\section{Number of exposure measurements}

Neighbourhood exposure measurements are more difficult to set in time than outcome measurements because they involve both the geographical location of the participants (generally in the form of an address, postal code or census area) and the contextual characteristics of their neighbourhood (eg, walkability, safety and greenness). Researchers can collect both pieces of information simultaneously or at different times. For example, Richardson $e t a l^{80}$ collected crime data from the city of Pittsburgh up to 2 years before the baseline year and also at the time of address collection from the participants in order to assess long term neighbourhood exposure and its effect on BMI. Other studies did not simultaneously collect participant addresses and examine neighbourhood characteristics simply because no neighbourhood data were available at the baseline year. For example, Wasfi et al ${ }^{89}$ linked the 2012 Walkscore data to address records from 1994 to 1995 since 
Table 3 Number of associations measured in selected studies and per cent of statistically significant associations by indicator type

$\begin{array}{ll}\text { Indicator type } & \text { Associations } \\ & \mathrm{n} \text { (\% of all } \\ \text { associations in } \\ \text { study) }\end{array}$

$\begin{array}{lrlrl}\text { Food environment } & 223 & (46.4) & 54 & (24.2) \\ \text { Deprivation } & 66 & (13.7) & 18 & (27.3) \\ \text { Green space } & 40 & (8.3) & 8 & (20.0) \\ \begin{array}{l}\text { Composite index } \\ \text { socioeconomic }\end{array} & 34 & (7.0) & 21 & (61.8) \\ \text { Security } & 25 & (5.2) & 2 & (8.0) \\ \text { Perceived } & 23 & (4.8) & 4 & (17.4)\end{array}$

environment

\begin{tabular}{|c|c|c|c|c|}
\hline $\begin{array}{l}\text { Physical activity } \\
\text { establishment }\end{array}$ & 15 & (3.1) & 4 & (26.7) \\
\hline Walkability & 12 & $(2.5)$ & 1 & (8.3) \\
\hline $\begin{array}{l}\text { Composite index } \\
\text { built environment }\end{array}$ & 10 & (2.1) & 5 & (50.0) \\
\hline Land use & 9 & $(1.9)$ & 2 & (22.2) \\
\hline $\begin{array}{l}\text { Transportation } \\
\text { infrastructure }\end{array}$ & 6 & (1.3) & 4 & $(66.7)$ \\
\hline Density & 5 & (1.0) & 2 & $(40.0)$ \\
\hline $\begin{array}{l}\text { Racial } \\
\text { composition }\end{array}$ & 4 & $(0.8)$ & 2 & $(50.0)$ \\
\hline $\begin{array}{l}\text { Distance to } \\
\text { landmark }\end{array}$ & 2 & $(0.4)$ & 2 & $(100.0)$ \\
\hline Other & 2 & $(0.4)$ & 2 & (100.0) \\
\hline Foreclosure & 2 & $(0.4)$ & 1 & $(50.0)$ \\
\hline Sprawl & 2 & $(0.4)$ & 0 & $(0.0)$ \\
\hline $\begin{array}{l}\text { Prevalence of } \\
\text { health behaviour }\end{array}$ & 1 & $(0.2)$ & 1 & (100.0) \\
\hline All & 481 & & 133 & \\
\hline
\end{tabular}

historical Walkscore data were unavailable for that same period.

Studies including only one measurement of the geographical localisation of the participants were the most common $(n=29)$, followed by studies including two measurements $(n=17)$. The highest number of exposure assessments was reported by Murray and coauthors, ${ }^{72}$ who used a 20 year residential history questionnaire to assess the influence of poverty on BMI. They interpolated census-tract poverty for every month between three US censuses for every participant.

\section{Residential mobility}

The residential mobility of participants is another characteristic related to time, as changes in residential location can contribute to changes in exposure to contexts. The vast majority $(n=52,79 \%)$ of the studies included both participants who still remained at the same residence

at the time of the follow-up (stayers) and participants who had changed residences (movers). Six studies (9\%) that included both stayers and movers in their sample presented a stratified analysis for residential mobility status. A few studies $(\mathrm{n}=12,18 \%)$ included samples composed of participants who stayed in the same neighbourhood for the entire duration of the follow-up period. Only two studies $(3 \%)$ had samples composed of only people who moved during the follow-up period (movers).

\section{Change in neighbourhood characteristics}

Another important characteristic linked to the longitudinal designs we examined is whether or not neighbourhood context was considered a time-varying quantity; that is, regardless of whether or not participants changed their residential location, did the studies examine how the characteristics of the neighbourhood changed over time? Less than half of the studies $(n=28)$ considered the temporal changes in neighbourhood context. There were several reasons that were provided for not measuring changes in neighbourhood characteristics when two residential location measurements were collected. These reasons included the absence of historical data, such as the Walkscore, ${ }^{40} 89$ or the availability of data at only one time during the follow-up period, such as through a census or land survey. ${ }^{4657756}$

\section{Statistical analysis}

Among the included publications, three main types of statistical analysis were applied to take into consideration the longitudinal structure of repeated measures. The most prevalent type of statistical analysis was multilevel model $(n=28)$, which use a nested structure to allow within-individual random variation. ${ }^{97}$ Multilevel models in included publications were composed of a combination of two to four levels, out of five possible levels (waves of the survey, individuals, family, neighbourhoods and larger geographical area). The second most common statistical analysis type was the use of linear, logistic or ordinal regression $(n=13)$ to perform an analysis of change in a continuous, dichotomic or ordinal OP. The third most frequent type of statistical analysis was fixed effect model $(\mathrm{n}=8)$, which uses each individual as is own control to account for unmeasured time-invariant characteristics. Two studies also used first-difference models similar to fixed effects models. The remaining studies used less common statistical strategies such as structural equations and spatial analysis or a combination of two types.

\section{Typology of study designs}

After examining the selected studies, we identified a threecategory typology based on how outcomes and exposures were considered, related to time: time-varying outcome and fixed exposure (VO-FE) studies, fixed outcome and time-varying exposure (FO-VE) studies, and time-varying outcome and time-varying exposure (VO-VE) studies.

In reality, both obesity and neighbourhood exposures are time-varying. However, while planning a longitudinal study, the researchers considered their research questions 
and the data that were available in order to decide whether their statistical model should be based on fixed or timevarying outcomes and exposures. If only one measurement was collected for outcome or exposure, then this part of the design was considered as fixed. The outcome was considered time-varying when repeated measurements of $\mathrm{OP}$ were reported. The context was considered time-varying when either or both the geographical localisation of participants and the neighbourhood characteristics were repeatedly measured over time. The fixed outcome and fixed exposure design (FO-FE) was implicitly excluded from this review since according to the eligibility criteria, no longitudinal studies applied this type of design.

Of the 28 studies using a VO-FE design, 18 only collected two measurements for the outcome using a typical baseline and follow-up design. Other studies used up to seven outcome measurements. ${ }^{45}$ In general, the sole contextual measurement from these studies was synchronised with baseline outcome measurements, but Auchincloss et al. ${ }^{32}$ synchronised a contextual measurement with the third of four clinical assessments of BMI in order to measure the impact of perceived walkability and food environment.

The most prevalent type of design was the VO-VE type with time-varying outcomes and time-varying exposures, which included 32 studies. Of those, 27 had the same number of outcome and exposure measurements (either geographical localisation or context characteristics). Hirsch et $a l^{55}$ for example, used a US sample to measure BMI, waist circumference, geographical location and contextual characteristics at five points in time to examine the association between built environment and obesity. Twenty-four studies measured the characteristics of context and their changes over time, while the others examined participant residential mobility to yield changes in exposure.

The FO-VE design was the least prevalent type of study. Six authors used this type of design, two of them in randomised social experiments from the Moving to Opportunity study, ${ }^{43}$ and two others were focused on neighbourhood poverty trajectories. ${ }^{445}$

\section{Qualitative synthesis of results}

Although the objective of this review was mainly to examine longitudinal designs, a qualitative synthesis of the associations is presented to summarise the results obtained from the selected studies.

For each study, all associations were qualified based on statistical significance (at a level of 5\%) and expected direction (as defined by the author). For studies using multiple models, results from the final and fully adjusted models were used. For articles measuring more than one association $(n=46)$, an aggregated indicator was created to qualify the overall study findings, based on the criteria from two previous reviews, ${ }^{989}$ and is presented in table 4 .

Table 2 summarises the overall findings of the reviewed studies according to their different characteristics. Of all the papers included in the review $(n=66), 45 \% \quad(n=30)$ reported a majority of non-significant associations and $35 \%(n=23)$ reported a majority of significant associations
Table 4 Criteria used to define overall study findings based on the associations measured

\begin{tabular}{lll}
$\begin{array}{l}\text { Overall study } \\
\text { findings }\end{array}$ & $\begin{array}{l}\text { Statistical } \\
\text { significance } \\
\text { reported }\end{array}$ & $\begin{array}{l}\text { Direction } \\
\text { reported }\end{array}$ \\
$\begin{array}{l}0 \%-33 \% \text { statistically } \\
\text { significant } \\
\text { associations }\end{array}$ & $\begin{array}{l}\text { Inverse or } \\
\text { expected }\end{array}$ \\
Mixed & $\begin{array}{l}34 \%-59 \% \\
\text { statistically significant } \\
\text { associations }\end{array}$ & expected \\
Expected & $\begin{array}{l}\text { More than } 60 \% \\
\text { statistically significant } \\
\text { associations }\end{array}$ & Expected \\
Inverse & $\begin{array}{l}\text { More than } 60 \% \\
\text { statistically significant } \\
\text { associations }\end{array}$ & Inverse \\
\hline
\end{tabular}

in the expected direction. The results were mixed for $20 \%$ of the papers, as they did not indicate a majority of significant, non-significant associations or inverse of the expected result.

When considering basic characteristics, studies that used waist circumference as an outcome measure, studies that measured socioeconomic neighbourhood exposure and studies with fixed outcomes and varying exposure resulted in more than $60 \%$ of aggregated associations that were statistically significant in the expected direction. Categories with fewer than five studies were not considered for this analysis, as presented in table 2.

Table 3 shows the results of the 481 disaggregated associations grouped by indicator type. Overall, composite indexes of the socioeconomic environment and indicators of transportation infrastructure revealed more than $60 \%$ of the statistically significant associations, all in the expected direction. Groups of indicators with fewer than five associations were not considered for this analysis.

\section{DISCUSSION}

\section{Main findings}

\section{Basic characteristics}

We conducted a systematic search of the scientific literature that examined associations between neighbourhood characteristics and obesity outcomes and found 66 papers. These papers included some form of longitudinal design with repeated measures of outcome and/or repeated measures of exposure. Most of the papers that were selected for our review were published very recently. This rapid increase in the number of papers published in this area of research reflects a more general trend in studies about neighbourhood effect on health as observed by Oakes et al, ${ }^{100}$ who in 2005 also revealed a substantial increase in such publications. However, this trend may also be due to the overall accelerated pace of publications that has been observed across most scientific domains. ${ }^{101}$ 
There have been many calls to improve the research on neighbourhood effect on health over the last 20 years. ${ }^{10172123100102}$ In addition to the longitudinal designs, which were the main focus of this review, we found that the more common suggestions for design improvement (conducting more studies on population subgroups, using adequate OPs, better identifying and defining neighbourhoods) were taken into account in at least a few of the studies among the 66 that were selected.

Ding and Gebel ${ }^{21}$ suggested that conducting more studies focused on populations outside the USA and on population groups such as women and ethnic minorities is a potential way to improve overall neighbourhood effect research. Although most studies used samples from Western, Educated, Industrialised, Rich and Democratic (WEIRD) populations ${ }^{103}$, a few of them focused on specific groups defined by gender, race, age or immigration status.

We also found that most of the studies selected BMI as an OP. Some authors have suggested that BMI does not accurately reflect the distribution of fat mass throughout the body, a factor that is hypothesised to have a substantial impact on the risk of cardiovascular disease and insulin resistance. ${ }^{104}$ The use of waist circumference measurements is recommended at the individual level, ${ }^{105}{ }^{106}$ but this information is rarely available at the population level.

The studies in this review used diverse indicators to describe contextual exposure. The large variety of indicators in these studies makes it difficult to compare studies and draw conclusions for each type of indicator. Mackenbach $e t a l,{ }^{10}$ in a review of studies examining the association between the built environment and weight, made a similar observation for both cross-sectional and longitudinal studies. However, in our review, we observed that this was not the case for food environment and deprivation. These two categories combined amounted to more than half of the associations measured in the selected studies. The popularity of food environment indicators suggests that research on diet-related behaviours attracts more interest among the scientific community than physical activity and its determinants. ${ }^{107}$ This may be because food availability data can be more easily collected than data on opportunities to participate in physical activity. Or perhaps because researchers observe the synchronicity between the changes in global food systems and the onset of the obesity epidemic to be an indication that the food environment could be the main influence for global weight gain. ${ }^{108}$ The long history of literature linking socioeconomic status and cardiovascular risk factors ${ }^{100} 109110$ and the availability of historical individual socioeconomic data in national censuses may have also motivated numerous researchers to examine deprivation. When we looked specifically at the indicators examined in these two prevailing categories (food environment and deprivation), there was a wide diversity of indicators within the categories that made it difficult to compare studies.

\section{Longitudinal characteristics}

As the main focus of this review, we first summarised how exposures and outcomes were set in time by applying a typology comprising three categories according to the longitudinal nature of the exposures and the outcomes. Using this typology allowed us to identify two key points: what the studies measured and what biases they attempted to address.

Studies with VO-FE are generally designed to control for selection bias. Recording participant OP at an initial baseline exam, follow-up and sometimes in between limits the possibility that OP differences between individuals were only due to their OP prior to starting the study. This is an important improvement from cross-sectional studies. Some studies in this review reported contrasting results between cross-sectional and longitudinal data. Albrecht et $a e^{30}$ observed associations between the baseline waist circumferences and neighbourhood food resources. However, they found no associations when using the changes in waistline circumference. Lee $e t a b^{64}$ observed inconsistent results for the cross-sectional and longitudinal associations between intersection density, food store density and green space and VAT. Most studies with a VO-FE design used multilevel models to account for intraindividual variability.

FO-VE studies are designed to examine life course changes in neighbourhood exposure or changes in neighbourhood characteristics. As early as 2001, Diez Roux ${ }^{23}$ recognised the importance of examining 'the cumulative or interacting effects of neighbourhood environments measured at different times over the life course, the effects of duration of exposure to certain neighbourhood conditions, the effects of changes over time in neighbourhood characteristics, and the impact of moving from one neighbourhood to another'. Our review found that every aspect of the longitudinal neighbourhood effect that was suggested by Diez Roux has been the focus of at least one of the selected studies. Most of the studies in this group used linear or logistic regression to estimate the effect of a change in the exposure or an exposure trajectory on an OP.

The VO-VE design, which was applied in the largest number of studies in this review, controls both for selection bias and life course exposure. For example, Burdette and Needham ${ }^{43}$ examined both temporal sequencing and life course and showed using a growth curve model that in a population of adolescents from the USA, those who lived in more disadvantaged neighbourhoods at baseline gained weight at a faster rate than those from a less disadvantaged neighbourhood. Leonard et $a t^{65}$ demonstrated that the conditions of neighbourhood change was related to changes in weight only among those who did not move from their neighbourhood, thus controlling for self-selection bias and life course changes in neighbourhood exposure. As fixed effects models control for time-invariant factors and require a change in exposure, all the studies using fixed effects models were found in this type of longitudinal designs. Multilevel models were also used to analyse VO-VE designs, and a few studies ${ }^{41447789}$ presented results for both fixed effects and multilevel models. Some authors ${ }^{37} 59$ also took advantage of multiple exposure measurements to build a cross-classified multilevel model where individuals were 
not nested in one neighbourhood but moved in time and were cross-classified into many neighbourhoods.

The 'fixed-varying' typology highlights the numerous research questions in the selected studies. Some studies posed research questions with particularities beyond the scope of this review, such as mediating behaviours or individual characteristics. But we could list at least six research questions directly related to neighbourhood effect on obesity with some degree of longitudinal variation:

- What is the effect of neighbourhood characteristics on OP change?

- What is the effect of neighbourhood characteristics on OP trajectory?

- What is the effect of neighbourhood characteristics change on OP change?

- What is the effect of moving to another neighbourhood on OP?

- What is the effect of neighbourhood trajectory on OP?

- What is the effect of a neighbourhood intervention on obesity?

Each one of these questions is relevant and illustrates one particular aspect of obesity and neighbourhood evolution. However, the longitudinal characteristics added even more variety to the diverse neighbourhood indicators, neighbourhood definitions and OPs previously described, which makes it more difficult to draw meaningful conclusions that may be helpful for intervention design.

\section{Qualitative synthesis of results}

Although this was not the main focus of our review, we found no strong evidence on neighbourhood effects on obesity in the longitudinal studies. Only 23 studies (35\%) yielded statistically significant results in the expected direction. However, this does not necessarily indicate that neighbourhood context has no effect, but that the specific characteristics of the neighbourhood and how they are measured are important.

In terms of contextual measurements, we found that studies reporting socioeconomic indicators of context yielded the majority of significant associations, whereas studies on the built environment yielded the majority of non-significant association (table 2). This may be because contextual socioeconomic indicators do in fact have a stronger effect on obesity or that associations with socioeconomic indicators are biassed by more closely correlated individual socioeconomic indicators that are difficult to control for. This adds to the general findings from literature reviews that these results are generally equivocal. Black and Macinko ${ }^{17}$ observed that economic resources and physical activity features of the neighbourhood are significantly associated with obesity, while the associations between income inequality and racial composition were mixed, and food availability associations were inconsistent. Leal and Chaix ${ }^{111}$ reported associations that were remarkably to reasonably consistent in all four categories (sociodemographic environment, physical environment, services and social interaction). Mackenbach $e t$ $a l^{10}$ reported mixed results for the physical environment.
When considering the obesity outcome measurement, our review shows that studies using waist circumference, although few in number, yielded more statistically significant associations than studies using only BMI. This could be explained by the fact that the distribution of fat may be differentially influenced by lifestyle choices induced by neighbourhood characteristics (ie, increase in muscular mass or decrease in visceral fat vs subcutaneous fat) ${ }^{104112-114}$ or that the studies using waistline measurements could have characteristics (number of participants, follow-up length and measurement quality), which could be associated with more statistical associations in the expected direction.

Finally, the type of design, whether using fixed or varying outcomes and exposures, did not seem to influence the significance or the direction of the association between the neighbourhood exposure and the obesity outcome. Studies with FO-VE did yield more statistically significant results than other types of longitudinal designs, but no definitive conclusions can be drawn due to the small number of studies. More studies of this type could contribute to better knowledge about neighbourhood effects on obesity, but authors of such studies should be aware that there is less control over self-selection bias when the follow-up period is short or the exposure is not randomised.

\section{Strengths and weaknesses}

We reviewed studies that were selected through a comprehensive research strategy. We also included a few papers that were cited in relevant publications. The selection criteria were designed to focus on observational studies. In strictly following the search strategy, we included some experimental and trial studies that appeared in our search results. ${ }^{42} 48586895$ However, these results could not be considered as a comprehensive appreciation of experimental schemes and could, therefore, be the topic of a review paper of their own. ${ }^{115}$

A person's weight status can vary greatly over his or her life course, with some periods and determinants playing more critical roles in the potential development of obesity. ${ }^{26} 116$ Therefore, although some authors have suggested that neighbourhood effects are stronger when considering trajectories that include childhood, we have decided to limit this scoping review to measuring obesity in adults, ${ }^{117}$ for uniformity. This restriction likely limited the number of eligible publications and reduced the number of longitudinal designs to examine, but it also reduced the heterogeneity among the selected studies and likely facilitated greater comparability among them, considering that OP cut-off values are different for adults and children. ${ }^{118}$

We also chose to limit our review to studies that focused on residential neighbourhoods, despite research showing that they are not the only source of contextual exposure in a population. ${ }^{102}$ Accessibilty to GPS (Global Positioning System) technologies have allowed a number of studies to examine activity space and better account for the environmental exposure of individuals. This environmental exposure includes the daily mobility of participants who are exposed to neighbourhoods around their 
home, around their workplace, or other destinations related to their activities. One study ${ }^{59}$ in our review found that accounting for activity space and the time spent in different neighbourhoods do influence the impact on obesity risk. Extending neighbourhood effect research beyond residential environments could help draw a more complete picture of how neighbourhoods and obesity status interact in time and space.

\section{Unanswered questions}

Better understanding longitudinal designs used in studies on neighbourhood effect on obesity prompts questions that cannot be answered in this review. The most obvious one would be whether quantitative analysis of the results of longitudinal studies can be applied. Restricting the reviews to a specific category of indicators, such as the food environment or deprivation or a specific type of design, could possibly provide enough homogeneity to perform such analyses. This would facilitate a quality analysis among studies, which was not possible in this review. Appraising statistical models, the length of follow-up periods, the number of measurements and population size would be helpful not only for selecting studies for a systematic review but also for suggesting quality standards for future longitudinal studies.

\section{Implications for future research}

One of the biggest challenges in conducting this review was the general difficulty in identifying the longitudinal characteristics in the selected studies. This reflects the challenging task of identifying and reporting every aspect of a study that can be influenced by time, and the difficulty in connecting these longitudinal characteristics with a specific research question. One of the most obvious examples is the residential mobility status of a population. In some articles, a group's choice to move or to stay in the same location was made clear and was sometimes even stated in the publication's title ${ }^{636595}$ or research question. ${ }^{76}$ But other authors neglected to mention the mobility status of their population or gave very little information about this factor, making it difficult to interpret the study's results and their significance. Similarly, some publications provided very few details about changes in neighbourhood characteristics or the time that neighbourhood characteristic measurements were collected. Therefore, we suggest that future studies on longitudinal characteristics of neighbourhood effects should report the following items whenever possible:

- Mobility status: specify whether participants moved residential locations during the follow-up period, stayed in the same residential location or whether the sample contains both types of mobility statuses.

- Time of residential location measurement: report time (date or wave) at which the residential neighbourhood of participants was localised.

- Time of neighbourhood characteristics measurements: report time at which the data describing neighbourhood characteristics were collected. Specify if neighbourhood characteristics vary in time (multiple neighbourhood characteristic measurements).
The availability of data describing exposures or outcomes is an important obstacle when conducting quality longitudinal studies. Acquiring access to repeated measures of BMI or waist circumference that are linked to high-quality retrospective neighbourhood measurements is highly challenging outside large-scale initiatives and especially outside WEIRD populations. Even with access to this information, capturing measurements that are more representative of neighbourhoods, such as the perceived neighbourhood or activity space, is a challenging task. It is worth considering the use of new technologies such as GPS data from mobile phones, geolocated data from social media, satellite imaging ${ }^{73}$ and administrative open data as they become more available to researchers. ${ }^{119} 120$

\section{CONCLUSION}

Our scoping review, aimed at characterising the designs of longitudinal studies examining neighbourhood effects on obesity, identified 66 studies that fit our eligibility criteria. Overall, these longitudinal study designs were mostly intended to control for self-selection bias, although a fair number of studies also took life course exposure into consideration. The studies were very diverse in terms of the questions asked, indicators used and designs proposed, which limited the potential for conducting quantitative reviews of the results. On the other hand, the populations that were studied lacked diversity, suggesting that future studies should expand their interest to those outside WEIRD populations. Additionally, we have proposed improvements for reporting longitudinal characteristics that could help authors design future longitudinal studies.

The diversified longitudinal study designs examined in this review reveal the intricate pathways in which the neighbourhood and obesity may interact with time. Identifying these pathways is indispensable in the discussion about causality. However, at this time, they also compound the overwhelming diversity of neighbourhood effect designs, which is an issue that has been identified as potentially hindering researchers from uncovering information that may prove useful for clinical or urban practices.

\section{Author affiliations}

${ }^{1}$ Planning and Development Research Center, Université Laval, Quebec city, Québec, Canada

${ }^{2}$ Evaluation Platform on Obesity Prevention, Quebec Heart and Lung Research Institute, Quebec city, Québec, Canada

${ }^{3}$ School of Nutrition, Université Laval, Quebec city, Québec, Canada

${ }^{4}$ Quebec Heart and Lung Institute Research Centre, Université Laval, Quebec city, Québec, Canada

${ }^{5}$ Departement of Surgery, Université Laval, Quebec city, Québec, Canada ${ }^{6}$ Department of Civil, Geological and Mining Engineering, Polytechnique Montreal, Montreal, Québec, Canada

Acknowledgements The authors acknowledge the contribution of Frédérick Bergeron, who helped to design and update the systematic search strategy. In addition, the authors thank Ouindpanga Sekou Samadoulougou and Pierre Gagnon for their valuable insights on statistical approaches involved in longitudinal studies.

Contributors LL designed this study; acquired, analysed and interpreted the data; and wrote the article. SP participated in data acquisition and contributed important intellectual content to the article. AT and LB revised the article and contributed important intellectual content. AL participated in the study design, data 
interpretation and revision of the article, and contributed important intellectual content. EODW participated in the study design, revised the article and contributed important intellectual content.

Funding This research received funding from the Foundation Institut Universitaire de Cardiologie et Pneumologie de Québec (2019-Lebel-A), the Québec Support for People and Patient-Oriented Research and Trials Unit, the Fond de Recherche du Québec-Santé $(31022,35784)$ and the Canadian Institutes of Health Research (162482)

Competing interests AT and LB have received research funding from Johnson \& Johnson Medical Companies as well as Medtronic for studies unrelated to this manuscript.

Patient consent for publication Not required.

Provenance and peer review Not commissioned; externally peer reviewed.

Data availability statement All data relevant to the study are included in the article or uploaded as supplementary information.

Open access This is an open access article distributed in accordance with the Creative Commons Attribution Non Commercial (CC BY-NC 4.0) license, which permits others to distribute, remix, adapt, build upon this work non-commercially, and license their derivative works on different terms, provided the original work is properly cited, appropriate credit is given, any changes made indicated, and the use is non-commercial. See: http://creativecommons.org/licenses/by-nc/4.0/.

ORCID iD

Laurence Letarte http://orcid.org/0000-0001-8610-3999

\section{REFERENCES}

1 Glass TA, McAtee MJ. Behavioral science at the crossroads in public health: extending horizons, envisioning the future. Soc Sci Med 2006;62:1650-71.

2 Kumanyika SK, Parker L, Sim LJ. Bridging the evidence gap in obesity prevention: a framework to inform decision making. National Academies Press, 2010.

3 Swinburn B, Egger G, Raza F. Dissecting obesogenic environments: the development and application of a framework for identifying and prioritizing environmental interventions for obesity. Prev Med 1999;29:563-70.

4 Gotay CC, Katzmarzyk PT, Janssen I, et al. Updating the Canadian obesity maps: an epidemic in progress. Can J Public Health 2013;104:e64-8.

5 NCD Risk Factor Collaboration (NCD-RisC). Trends in adult bodymass index in 200 countries from 1975 to 2014 : a pooled analysis of 1698 population-based measurement studies with $19 \cdot 2$ million participants. Lancet 2016;387:1377-96.

$6 \mathrm{Ng} \mathrm{M}$, Fleming T, Robinson M, et al. Global, regional, and national prevalence of overweight and obesity in children and adults during 1980-2013: a systematic analysis for the global burden of disease study 2013. The Lancet 2014;384:766-81.

7 Abarca-Gómez L, Abdeen ZA, Hamid ZA, et al. Worldwide trends in body-mass index, underweight, overweight, and obesity from 1975 to 2016: a pooled analysis of 2416 population-based measurement studies in 128.9 million children, adolescents, and adults. The Lancet 2017;390:2627-42.

8 Lebel A, Pampalon R, Hamel D, et al. The geography of overweight in Quebec: a multilevel perspective. Can J Public Health 2009;100:18-23.

9 Malik VS, Willett WC, Hu FB. Global obesity: trends, risk factors and policy implications. Nat Rev Endocrinol 2013;9:13-27.

10 Mackenbach JD, Rutter H, Compernolle S, et al. Obesogenic environments: a systematic review of the association between the physical environment and adult weight status, the spotlight project. BMC Public Health 2014;14.

11 Papas MA, Alberg AJ, Ewing R, et al. The built environment and obesity. Epidemiol Rev 2007;29:129-43.

12 Booth KM, Pinkston MM, Poston WSC. Obesity and the built environment. J Am Diet Assoc 2005;105:110-7.

13 Feng J, Glass TA, Curriero FC, et al. The built environment and obesity: a systematic review of the epidemiologic evidence. Health Place 2010;16:175-90.

14 Garfinkel-Castro Aet al. The Built Environment and Obesity, in Metabolic Syndrome: A Comprehensive Textbook, R.S.. In: Ahima, 2016: 275-86.

15 Durand CP, Andalib M, Dunton GF, et al. A systematic review of built environment factors related to physical activity and obesity risk: implications for smart growth urban planning. Obesity Reviews 2011;12:e173-82

16 Casagrande SS, Whitt-Glover MC, Lancaster KJ, et al. Built environment and health behaviors among African Americans. Am J Prev Med 2009;36:174-81.

17 Black JL, Macinko J. Neighborhoods and obesity. Nutr Rev 2008;66:2-20.

18 Lachowycz K, Jones AP. Greenspace and obesity: a systematic review of the evidence. Obesity Reviews 2011;12:e183-9.

19 Lovasi GS, Hutson MA, Guerra M, et al. Built environments and obesity in disadvantaged populations. Epidemiol Rev 2009;31:7-20

20 Chandrabose M, Rachele JN, Gunn L, et al. Built environment and cardio-metabolic health: systematic review and meta-analysis of longitudinal studies. Obesity Reviews 2019;20:41-54.

21 Ding D, Gebel K. Built environment, physical activity, and obesity: what have we learned from reviewing the literature? Health Place 2012;18:100-5.

22 Merlo J. Contextual influences on the individual life course: Building a research framework for social epidemiology. Psychosocial Intervention 2011;20:109-18.

23 Diez Roux AV. Investigating neighborhood and area effects on health. Am J Public Health 2001;91:1783-9.

24 Kitamura R, Mokhtarian PL, Daidet L. A micro-analysis of land use and travel in five neighborhoods in the San Francisco Bay area. Transportation 1997;24:125-58.

25 Wheeler DC, Calder CA. Sociospatial Epidemiology: Residential History Analysis, in Handbook of Spatial Epidemiology. In: Lawson $A B$, ed. CRC Press, 2016.

26 Ben-Shlomo Y, Kuh D. A life course approach to chronic disease epidemiology: conceptual models, empirical challenges and interdisciplinary perspectives. Int J Epidemiol 2002;31:285-93.

27 Boscoe FP. The use of residential history in environmental health studies, in Geospatial Analysis of Environmental Health. Springer, 2011: 93-110.

28 Arksey H, O'Malley L. Scoping studies: towards a methodological framework. Int J Soc Res Methodol 2005;8:19-32.

29 Letarte L, Lebel A, Waygood EOD, et al. Longitudinal designs to study neighbourhood effects on the development of obesity: a scoping review protocol. BMJ Open 2018;8:e017704.

30 Albrecht SS, Osypuk TL, Kandula NR, et al. Change in waist circumference with longer time in the United States among Hispanic and Chinese immigrants: the modifying role of the neighborhood built environment. Ann Epidemiol 2015;25:767-72.

31 Arcaya M, Glymour MM, Chakrabarti P, et al. Effects of Proximate Foreclosed Properties on Individuals' Weight Gain in Massachusetts, 1987-2008. Am J Public Health 2013;103:e50-6.

32 Auchincloss AH, Mujahid MS, Shen M, et al. Neighborhood healthpromoting resources and obesity risk (the multi-ethnic study of atherosclerosis). Obesity 2012;12.

33 Auerbach BJ, Katz R, Tucker K, et al. Factors associated with maintenance of body mass index in the Jackson heart study: a prospective cohort study secondary analysis. Prev Med 2017;100:95-100.

34 Barrientos-Gutierrez T, Moore KAB, Auchincloss AH, et al. Neighborhood physical environment and changes in body mass index: results from the multi-ethnic study of atherosclerosis. Am J Epidemiol 2017;186:1237-45.

35 Berry TR, Spence JC, Blanchard C, et al. Changes in BMI over 6 years: the role of demographic and neighborhood characteristics. Int J Obes 2010;34:1275-83.

36 Berry TR, Spence JC, Blanchard CM, et al. A longitudinal and cross-sectional examination of the relationship between reasons for choosing a neighbourhood, physical activity and body mass index. Int J Behav Nutr Phys Act 2010;7:57.

37 Block JP, Christakis NA, O'Malley AJ, et al. Proximity to food establishments and body mass index in the Framingham Heart Study offspring cohort over 30 years. Am J Epidemiol 2011;174:1108-14.

38 Blok DJ, de Vlas SJ, van Empelen P, et al. Changes in smoking, sports participation and overweight: does neighborhood prevalence matter? Health Place 2013;23:33-8.

39 Boone-Heinonen J, Diez-Roux AV, Goff DC, et al. The neighborhood energy balance equation: does neighborhood food retail environment + physical activity environment = obesity? the cardia study. PLoS One 2013;8:e85141.

40 Braun LM, Rodríguez DA, Evenson KR, et al. Walkability and cardiometabolic risk factors: cross-sectional and longitudinal associations from the multi-ethnic study of atherosclerosis. Health Place 2016;39:9-17.

41 Braun LM, Rodriguez DA, Song Y, et al. Changes in walking, body mass index, and cardiometabolic risk factors following residential 
relocation: longitudinal results from the cardia study. Journal of Transport \& Health 2016;3:426-39.

42 Brown BB, Werner CM, Tribby CP, et al. Transit use, physical activity, and body mass index changes: objective measures associated with complete street Light-Rail construction. Am J Public Health 2015;105:1468-74.

43 Burdette AM, Needham BL. Neighborhood environment and body mass index trajectories from adolescence to adulthood. Journal of Adolescent Health 2012;50:30-7.

44 Christine PJ, Moore K, Crawford ND, et al. Exposure to neighborhood Foreclosures and changes in cardiometabolic health: results from MESA. Am J Epidemiol 2017;185:106-14.

45 Arantxa Colchero M, Bishai D. Effect of neighborhood exposures on changes in weight among women in Cebu, Philippines (1983-2002). Am J Epidemiol 2008;167:615-23.

46 Coogan PF, Cozier YC, Krishnan S, et al. Neighborhood socioeconomic status in relation to 10-year weight gain in the black women's health study. Obesity 2010;18:2064-5.

47 Coogan PF, White LF, Evans SR, et al. Longitudinal assessment of urban form and weight gain in African-American women. Am J Prev Med 2011;40:411-8.

48 Cummins S, Flint E, Matthews SA. New neighborhood grocery store increased awareness of food access but did not alter dietary habits or obesity. Health Aff 2014;33:283-91.

49 Do DP, Zheng C. A marginal structural modeling strategy investigating short and long-term exposure to neighborhood poverty on BMI among U.S. black and white adults. Health Place 2017;46:201-9.

50 Eid J, Overman HG, Puga D, et al. Fat City: Questioning the relationship between urban sprawl and obesity. J Urban Econ 2008:63:385-404.

51 Feng X, Wilson A, Bigger G. Getting bigger, quicker? gendered socioeconomic trajectories in body mass index across the adult lifecourse: a longitudinal study of 21,403 Australians. PLoS One 2015;10:e0141499.

52 Gebel K, Bauman AE, Sugiyama T, et al. Mismatch between perceived and objectively assessed neighborhood walkability attributes: prospective relationships with walking and weight gain. Health Place 2011:17:519-24.

53 Gibson DM. The neighborhood food environment and adult weight status: estimates from longitudinal data. Am J Public Health 2011;101:71-8

54 Halonen JI, Kivimäki M, Pentti J, et al. Green and blue areas as predictors of overweight and obesity in an 8-year follow-up study. Obesity 2014;22:1910-7.

55 Hirsch JA, Moore KA, Barrientos-Gutierrez T, et al. Built environment change and change in BMl and waist circumference: multi-ethnic study of atherosclerosis. Obesity 2014;22:2450-7.

56 Jones M, Huh J. Toward a multidimensional understanding of residential neighborhood: a latent profile analysis of Los Angeles neighborhoods and longitudinal adult excess weight. Health Place 2014;27:134-41.

57 Joost S, Duruz S, Marques-Vidal P, et al. Persistent spatial clusters of high body mass index in a Swiss urban population as revealed by the 5-year GeoCoLaus longitudinal study. BMJ Open 2016;6:e010145.

58 Kapinos KA, Yakusheva O, Eisenberg D. Obesogenic environmenta influences on young adults: evidence from College dormitory assignments. Econ Hum Biol 2014;12:98-109.

59 Kimbro RT, Sharp G, Denney JT. Home and away: area socioeconomic disadvantage and obesity risk. Health Place 2017:44:94-102.

60 Kwarteng JL, Schulz AJ, Mentz GB, et al. Independent effects of neighborhood poverty and psychosocial stress on obesity over time. Journal of Urban Health 2017;94:791-802.

61 Kwarteng JL, Schulz AJ, Mentz GB, et al. Neighbourhood poverty, perceived discrimination and central adiposity in the USA: independent associations in a repeated measures analysis. $J$ Biosoc Sci 2016;48:709-22.

62 Lamb KE, Thornton LE, Olstad DL, et al. Associations between major chain fast-food outlet availability and change in body mass index: a longitudinal observational study of women from Victoria, Australia. BMJ Open 2017;7:e016594.

63 Laraia BA, Downing JM, Zhang YT, et al. Food environment and weight change: does residential mobility matter?: the diabetes study of northern California (distance). Am J Epidemiol 2017:185:743-50.

64 Lee JJ, Hwang S-J, Mutalik K, et al. Association of built environment characteristics with adiposity and glycaemic measures. Obesity Science \& Practice 2017;3:333-41.
65 Leonard T, Ayers C, Das S, et al. Do neighborhoods matter differently for movers and non-movers? analysis of weight gain in the longitudinal Dallas heart study. Health Place 2017;44:52-60.

$66 \mathrm{Li} \mathrm{Fet} \mathrm{al.} \mathrm{Built} \mathrm{environment} \mathrm{and} \mathrm{1-year} \mathrm{change} \mathrm{in} \mathrm{weight} \mathrm{and} \mathrm{waist}$ circumference in middle-aged and older adults. American Journal of Epidemiology 2009;169:401-8.

67 Lippert AM, Evans CR, Razak F, et al. Associations of continuity and change in early neighborhood poverty with adult cardiometabolic biomarkers in the United States: results from the National longitudinal study of adolescent to adult health, 1995-2008. Am J Epidemiol 2017;185:765-76.

68 Ludwig J, Sanbonmatsu L, Gennetian L, et al. Neighborhoods, obesity, and diabetes--a randomized social experiment. $N$ Engl $J$ Med 2011;365:1509-19.

69 Mendez DD, Gary-Webb TL, Goode R, et al. Neighborhood factors and six-month weight change among overweight individuals in a weight loss intervention. Preventive Medicine Reports 2016;4:569-73.

70 Meyer KA, Boone-Heinonen J, Duffey KJ, et al. Combined measure of neighborhood food and physical activity environments and weight-related outcomes: the cardia study. Health Place 2015;33:9-18.

71 Mujahid MS, Diez Roux AV, Borrell LN, et al. Cross-sectional and longitudinal associations of BMI with socioeconomic characteristics. Obes Res 2005;13:1412-21.

72 Murray ET, Diez Roux AV, Carnethon M, et al. Trajectories of neighborhood poverty and associations with subclinical atherosclerosis and associated risk factors: the multi-ethnic study of atherosclerosis. Am J Epidemiol 2010;171:1099-108.

73 Picavet HSJ, Milder I, Kruize H, et al. Greener living environment healthier people?: exploring green space, physical activity and health in the Doetinchem cohort study. Prev Med 2016;89:7-14.

74 Jilcott Pitts SB, Keyserling TC, Johnston LF, et al. Examining the association between Intervention-Related changes in diet, physical activity, and weight as moderated by the food and physical activity environments among rural, southern adults. $J$ Acad Nutr Diet 2017; 117:1618-27.

75 Powell-Wiley TM, Ayers C, Agyemang P, et al. Neighborhood-leve socioeconomic deprivation predicts weight gain in a multi-ethnic population: longitudinal data from the Dallas heart study. Prev Med 2014;66:22-7.

76 Powell-Wiley TM, Cooper-McCann R, Ayers C, et al. Change in neighborhood socioeconomic status and weight gain. Am J Prev Med 2015;49:72-9.

77 Powell-Wiley TM, Moore K, Allen N, et al. Associations of neighborhood crime and safety and with changes in body mass index and waist circumference: the multi-ethnic study of atherosclerosis. Am J Epidemiol 2017;186:280-8.

78 Rachele JN, Kavanagh A, Brown WJ, et al. Neighborhood socioeconomic disadvantage and body mass index among residentially stable mid-older aged adults: findings from the habitat multilevel longitudinal study. Prev Med 2017;105:271-4.

79 Richardson AS, Meyer KA, Howard AG, et al. Multiple pathways from the neighborhood food environment to increased body mass index through dietary behaviors: a structural equation-based analysis in the cardia study. Health Place 2015;36:74-87.

80 Richardson AS, Troxel WM, Ghosh-Dastidar M, et al. Pathways through which higher neighborhood crime is longitudinally associated with greater body mass index. International Journal of Behavioral Nutrition and Physical Activity 2017;14.

81 Ruel E, Reither EN, Robert SA, et al. Neighborhood effects on BMI trends: examining BMI trajectories for black and white women. Health Place 2010;16:191-8.

82 Rummo PE, Guilkey DK, Ng SW, et al. Does unmeasured confounding influence associations between the retail food environment and body mass index over time? the coronary artery risk development in young adults (cardia) study. Int J Epidemiol 2017; 46:1456-64

83 Sarkar C, Gallacher J, Webster C. Built environment configuration and change in body mass index: the Caerphilly prospective study (CAPS). Health Place 2013;19:33-44.

84 Sheehan CM, Cantu PA, Powers DA, et al. Long-Term neighborhood poverty trajectories and obesity in a sample of California mothers. Health Place 2017;46:49-57.

85 Stafford Met al. Deprivation and the development of obesity a multilevel, longitudinal study in England. American Journal of Preventive Medicine 2010;39:130-9.

86 Stoddard PJet al. Neighborhood deprivation and change in BMI among adults with type 2 diabetes. Diabetes Care 2013;36:1200-8. 
87 Sugiyama T, Niyonsenga T, Howard NJ, et al. Residential proximity to urban centres, local-area walkability and change in waist circumference among Australian adults. Prev Med 2016;93:39-45.

88 Sund ER, Jones A, Midthjell K. Individual, family, and area predictors of BMI and BMI change in an adult Norwegian population: findings from the HUNT study. Soc Sci Med 2010;70:1194-202.

89 Wasfi RA, Dasgupta K, Orpana H, et al. Neighborhood Walkability and body mass index trajectories: longitudinal study of Canadians. Am J Public Health 2016;106:934-40.

90 Xiao Q, Berrigan D, Keadle SK, et al. Neighborhood socioeconomic deprivation and weight change in a large U.S. cohort. Am J Prev Med 2017;52:e173-81.

$91 \mathrm{Xu} \mathrm{H}$, Short SE, Liu T. Dynamic relations between fast-food restaurant and body weight status: a longitudinal and multilevel analysis of Chinese adults. J Epidemiol Community Health 2013;67:271-9.

92 Zenk SN, Mentz G, Schulz AJ, et al. Longitudinal associations between observed and perceived neighborhood food availability and body mass index in a multiethnic urban sample. Health Educ Behav 2017:44:41-51.

93 Zenk SN, Tarlov E, Wing C, et al. Geographic accessibility of food outlets not associated with body mass index change among Veterans, 2009-14. Health Aff 2017;36:1433-42.

94 Zhang YT, Laraia BA, Mujahid MS, et al. Is a reduction in distance to nearest supermarket associated with BMI change among type 2 diabetes patients? Health Place 2016;40:15-20.

95 Zhao Z, Kaestner R, Xu X. Spatial mobility and environmental effects on obesity. Economics \& Human Biology 2014;14:128-40.

96 Rummo PE, Meyer KA, Green Howard A, et al. Fast food price, diet behavior, and cardiometabolic health: differential associations by neighborhood Ses and neighborhood fast food restaurant availability in the cardia study. Health Place 2015;35:128-35.

97 Twisk JW. Applied longitudinal data analysis for epidemiology: a practical guide. Cambridge University Press, 2013.

98 Ding D, Sallis JF, Kerr J, et al. Neighborhood environment and physical activity among youth. Am J Prev Med 2011;41:442-55.

99 Brown V, Moodie M, Carter R. Evidence for associations between traffic calming and safety and active transport or obesity: a scoping review. Journal of Transport \& Health 2017;7:23-37.

100 Oakes JM, Andrade KE, Biyoow IM, et al. Twenty years of neighborhood effect research: an assessment. Curr Epidemiol Rep 2015;2:80-7.

101 Unesco, Schlegel F. UNESCO science report: towards 2030. UNESCO Publ, 2015

102 Perchoux C, Chaix B, Brondeel R, et al. Residential buffer, perceived neighborhood, and individual activity space: new refinements in the definition of exposure areas - the record cohor study. Health Place 2016;40:116-22.
103 Henrich J, Heine SJ, Norenzayan A. The weirdest people in the world? Behav Brain Sci 2010;33:61-83.

104 Tchernof A, Després J-P. Pathophysiology of human visceral obesity: an update. Physiol Rev 2013;93:359-404.

105 World Health Organization,. Obesity: preventing and managing the global epidemic, 2000.

106 Després JP, Moorjani S, Lupien PJ, et al. Regional distribution of body fat, plasma lipoproteins, and cardiovascular disease. Arteriosclerosis 1990;10:497-511.

107 Rodgers A, Woodward A, Swinburn B, et al. Prevalence trends tell us what did not precipitate the US obesity epidemic. The Lancet Public Health 2018;3:e162-3.

108 Swinburn BA, Sacks G, Hall KD, et al. The global obesity pandemic: shaped by global drivers and local environments. The Lancet 2011;378:804-14

109 Kaplan GA, Keil JE. Socioeconomic factors and cardiovascular disease: a review of the literature. Circulation 1993;88:1973-98.

110 Suglia SF, Shelton RC, Hsiao A, et al. Why the neighborhood social environment is critical in obesity prevention. Journal of Urban Health 2016;93:206-12.

111 Leal C, Chaix B. The influence of geographic life environments on cardiometabolic risk factors: a systematic review, a methodological assessment and a research agenda. Obes Rev 2011;12:217-30.

112 Arsenault BJ, Lachance D, Lemieux I, et al. Visceral adipose tissue accumulation, cardiorespiratory fitness, and features of the metabolic syndrome. Arch Intern Med 2007;167:1518-25.

113 Després J-P, Obesity. Obesity and cardiovascular disease: weight loss is not the only target. Can J Cardiol 2015;31:216-22.

114 Vissers D, Hens W, Taeymans J, et al. The effect of exercise on visceral adipose tissue in overweight adults: a systematic review and meta-analysis. PLoS One 2013;8:e56415.

115 Mayne SL, Auchincloss AH, Michael YL. Impact of policy and built environment changes on obesity-related outcomes: a systematic review of naturally occurring experiments. Obes Rev 2015;16:362-75.

116 Ziyab AH, Karmaus W, Kurukulaaratchy RJ, et al. Developmental trajectories of Body Mass Index from infancy to 18 years of age: prenatal determinants and health consequences. J Epidemiol Community Health 2014;68:934-41.

117 Glass TA, Bilal U. Are neighborhoods causal? Complications arising from the 'stickiness' of ZNA. Soc Sci Med 2016;166:244-53.

118 Ogden CL, Flegal KM. Changes in terminology for childhood overweight and obesity. Natl Health Stat Report 2010;12:1-5.

119 Kwan M-P. The Limits of the Neighborhood Effect: Contextual Uncertainties in Geographic, Environmental Health, and Socia Science Research. Ann Am Assoc Geogr 2018;108:1482-90.

120 Ohmer MLet al. Measures for community and neighborhood research. 13. SAGE Publications, 2018. 